\title{
Vital resource should be open to all physicists
}

\section{Putting control in the hands of a few can enforce orthodoxy and stifle innovative ideas.}

Sir - Your News story "Rejected physicists

instigate anti-arXiv site" (Nature 432,

428-429; 2004) reports a response from

Paul Ginsparg, the founder of the preprint

server arXiv.org, to criticisms of its

publication policies. Ginsparg states that

the rules governing who can and cannot

publish are clearly stated on the site,

and that the archive is designed for

"communication among research

professionals, not as a mechanism

for outsiders to communicate to

that community".

The cases documented by myself and others on the ArchiveFreedom website show that there is more to the story.
The exclusion of particular individuals and particular ideas from arXiv appears to me to be deliberate. If a rule can be invoked in support, however tenuous the link, the rule is quoted; otherwise, submissions are simply 'deleted as inappropriate'. For example, having stated that a very distinguished physicist's strong support of a submission carried no weight because this physicist "was not intimately familiar with the work in question", the moderators simply ignored subsequent support from an endorser with publications on the same subject.

In another example, the moderators' response to the information that more than one eminent physicist had an interest in a subject that they wished to bar was: "We are always thrilled to hear when people find an avocation that keeps them off the streets and out of trouble."

ArXiv has become a vital communicative resource for the physics community. The moderators' attitude to any challenge to conventional thinking is likely to result in the loss to science of important innovative ideas. Radical changes are required in the way the archive is administered.

Brian D. Josephson

Department of Physics,

University of Cambridge,

Cambridge CB3 OHE, UK
Climate blog could score with newer hockey stick

Sir - In your Editorial "Welcome climate bloggers" and News story "Climatologists get real over global warming” (Nature 432, 933 and 937; 2004), the newly created RealClimate blog (www.realclimate.org) is introduced as a website battling distorted media coverage on global-warming research.

As a member of the climate-research community and inspired by your enthusiastic introduction, I navigated RealClimate with high expectations. I was, however, sadly disappointed by a posting by M. E. Mann on 4 December:

"Temperature variations in past centuries and the so-called 'Hockey Stick.'” Among other data, this included an overview of temperature change during the past millennium as reconstructed by various climate proxies including borehole data.

I cannot comment on the accuracy of the rest of the posting, but I was concerned to find that Figure 1, showing temperature change in the Northern Hemisphere, included an outdated and erroneous reconstruction of borehole data by M. E. Mann et al. (J. Geophys. Res. 108, 4203 ; 2003). In my view, the website should have used a later version (S. Rutherford and M. E. Mann, J. Geophys. Res. 109, D11107; 2004), which acknowledged an error in the earlier paper, or other more recent reconstructions. To be fair, the authors of the website added a correction after I drew their attention to this.

Your Editorial asserts that there is little reason to doubt that RealClimate's goal, "to provide solid scientific comment to journalists and other interested parties", can be reached. But you also warn of the dangers of "a rapid-rebuttal service, run with minimal peer review". Let us hope that future postings on RealClimate will fulfil our high expectations.

Shaopeng Huang

Department of Geological Sciences, University of Michigan, Ann Arbor, Michigan 48109-1063, USA

\section{Best way to protect rock art is to leave it alone}

Sir - Your News Feature about the Lascaux cave, "The film crew" (Nature 433, 100-101; 2005), expresses the hope that, thanks to new technologies, "tourists will get their chance to see the real version of this ancient site". Unfortunately, the history of Lascaux's conservation since its discovery in 1940 leads one to expect the opposite. Today, the cave is closed even to experts in rock art.

Contrary to your report, the cave's climate did not return to its original state after the 1963 closure. How could it? Several hundred cubic metres of soil had been removed between 1940 and 1958, when an air-conditioning system was installed. The green algae, mosses and bacteria were eventually eradicated from the walls, but the growth of small white calcite crystals on the surface caused by rises in temperature, humidity and carbonic gas associated with visitors to the caves could only be stopped, not reversed.

Lascaux remains extremely fragile. The 2001 invasion of the floor by white Fusarium fungi and the (fortunately limited) appearance of black spots on the ceiling remind us of the dangers of interfering with rock-art sites. The best technology for preserving them is to leave them alone. Luc Allemand ${ }^{\star}$, Paul G. Bahn $\dagger$

${ }^{\star}$ La Recherche, 4 rue du Texel, 75014 Paris, France $\uparrow 428$ Anlaby Road, Hull HU3 6QP, UK

\section{Online submission makes authors do all the work}

Sir - During the past two years, most of the leading scientific journals have switched to an electronic system for manuscript submission.

Superficially, this might seem to be progress. But in practice, the onus for the preparation of publication-quality manuscripts, particularly figures, has quietly switched from the journals to the authors, who are now expected to run mini-desktop publishing operations from their offices and laboratories.

The submission of a paper can now take days of fiddling with various computer programs, where once it took a few minutes to print a manuscript and shove it in an envelope. The end-product is no better, nor is publication any quicker, and page charges (for those journals operating that system) are as high as ever.

So just who has benefited, or profited, from the change? The authors or the journals? And how do scientists in lessdeveloped countries with older computer systems cope with the quixotic demands of the electronic systems?

The degree of user-unfriendliness varies from journal to journal (Nature's is far from the worst), but avoiding the most hassle-associated systems is now, in my case at least, a significant factor to be taken into account when choosing a journal for submission of a paper.

John P. Moore

Department of Microbiology and Immunology, Joan and Sanford I. Weill Medical College of Cornell University,

1300 York Avenue, W-805 New York,

New York 10021, USA 